\title{
Formação de jogadores profissionais de voleibol: relações entre atletas de elite e a especialização precoce
}

CDD. 20.ed. 796.073

796.325

http://dx.doi.org/10.1590/1807-55092014000200293
Renato Francisco Rodrigues MARQUES*

Celiane Pereira LIMA**

Camila de MORAES*

Myrian NUNOMURA*

Elaine Cristina SIMÕES ${ }^{* *}$
*Escola de Educação

Física e Esporte de

Ribeirão Preto, Universidade de São Paulo.

**Fundação Municipal

de Ensino Superior de

Bragança Paulista.

\section{Resumo}

Embora a literatura aponte malefícios da especialização esportiva precoce, sua aplicação permanece recorrente, embasada na crença que quanto mais cedo os treinos e a participação em competições se iniciarem, maiores serão as chances de sucesso no alto rendimento. 0 objetivo deste estudo foi investigar como ocorreu o processo de formação esportiva de 52 jogadores profissionais de voleibol masculino, atuantes no Campeonato Paulista e Superliga Nacional. 0 foco foi analisar a possível ocorrência de especialização precoce e de vivências esportivas diversificadas. Os dados foram coletados através de questionário por escrito e apresentados com estatística descritiva. Os resultados apontam que a maioria dos atletas não foi especializada precocemente e vivenciou práticas diversificadas durante sua formação, em diferentes modalidades esportivas. Os dados sinalizam para a tese que quando os treinamentos com foco nos resultados competitivos se iniciam após ou durante a puberdade há maiores chances de sucesso esportivo em comparação à especialização esportiva precoce.

PalavRas-chave: Especialização esportiva precoce; Voleibol; Especialização; Iniciação esportiva.

\section{Introdução}

O esporte assumiu, na sociedade contemporânea, certa responsabilidade frente à promoção de processos de desenvolvimento moral de crianças e jovens ${ }^{1-2}$, além da promoção de um estilo de vida ativo prevalente na idade adulta ${ }^{3-4}$. Neste sentido, existe certa expectativa, frente aos processos de formaçáo esportiva, para que contribuam com o desenvolvimento de sujeitos que, se não mostrarem-se aptos a atuarem no alto rendimento, ainda assim gostem da prática e insiram a mesma em seu cotidiano ${ }^{5}$.

A formação esportiva constitui-se de um processo de longo prazo ${ }^{6}$, que compóe as etapas de iniciação, especialização e alto rendimento ${ }^{7}$.

A iniciação esportiva é o período em que a criança ou jovem tem seus primeiros contatos com a prática regular e orientada de uma ou mais modalidades. É um processo complexo, que pode envolver desde procedimentos pedagógicos relacionados à socializaçáo e diversáo, passando pela preocupaçáo com a educação moral e o desenvolvimento de capacidades físicas e motoras, até atividades que tenham o resultado da competição esportiva como objeto central ${ }^{8-9}$. Assim como qualquer processo educacional, a iniciação esportiva caracteriza-se por componentes socioculturais que envolvem não apenas o jovem atleta, mas também todos os agentes sociais que o circundam e exercem influência sobre sua formação ${ }^{2}$, tais como treinadores, familiares, dirigentes, colegas, torcida, empresários.

Os objetivos e sentidos adotados pela prática na iniciação esportiva derivam, em grande parte, do modo como o profissional de Educação Física e Esporte direciona sua forma de atuaçáo. Muitos buscam resultados em curto prazo, especializam precocemente a criança em determinada modalidade e, assim, ignoram a fase de desenvolvimento em que ela se encontra ${ }^{10}$.

A especialização esportiva é definida, segundo BARBANTI ${ }^{11}$, como o processo no qual o indivíduo aprofunda seus conhecimentos e capacidades 
específicos em determinada modalidade. Quando este procedimento, prematuramente, envolve crianças durante a iniciação esportiva, tem-se como resultado a especialização esportiva precoce ${ }^{4}$, que pode ser definida: ...quando crianças são introduzidas, antes da fase pubertária, a um processo de treinamento planejado e organizado a longo prazo e que se efetiva em um mínimo de três sessões semanais, com o objetivo do gradual aumento do rendimento, além de participação periódica em competições esportivas $^{12}$ (p.45).

...envolvimento precoce em um esporte principal; normalmente ocorre durante a infância, com pequeno ou nenhum envolvimento com outras modalidades $^{13}$ (p.282).

A especialização esportiva precoce é um fenômeno que ocorre durante a iniciação esportiva de crianças, direcionando este processo às vivências ligadas ao mundo adulto. Consiste em uma forma de treinamento que não respeita as características da fase maturacional dos praticantes ${ }^{14}$, o que pode ser prejudicial para seu desenvolvimento global, provocar o abandono da prática ou até dificultar o êxito esportivo após a puberdade ${ }^{1,15}$.

Especializar atletas precocemente pode expôlos a certas situaçóes e fatores estressantes, além de favorecer o abandono da prática ${ }^{16-17}$. A literatura indica alguns prejuízos como possíveis consequências da especialização esportiva precoce, sendo eles de ordem física, como lesões ${ }^{17-20}$, social $^{21-22}$, emocional ${ }^{17-18,21}$ e motora ${ }^{10}$.

BAKER $^{23}$ destaca que a especialização esportiva precoce, vinculada à busca por resultados excelentes ainda na infância, não pode ser confundida com a participação lúdica de crianças em uma única modalidade esportiva. Para o autor, o sentido empregado à prática é o principal fator constituinte deste fenômeno. Gould ${ }^{24}$ completa esta ideia afirmando que não há problema na especialização esportiva realizada em circunstâncias favoráveis. $\mathrm{O}$ problema da especialização esportiva precoce é que ela acontece prematuramente em relação às etapas de desenvolvimento das crianças.

Embora haja exemplos de atletas que passaram por este processo e ainda assim atingiram a excelência esportiva, a precocidade em relação à busca por resultados atléticos é um procedimento que não aparenta relação com efeitos positivos no futuro ${ }^{6}$. A ocorrência de bons resultados esportivos na infância não garante, necessariamente, o mesmo sucesso em fases posterio$\mathrm{res}^{25}$. Com cautela e tendo como pano de fundo o desenvolvimento em longo prazo, a demonstração de aptidão atlética pode ser interpretada apenas e tão somente como um estágio inicial do desenvolvimento ${ }^{16}$.

Para GOULD ${ }^{24}$ e JAYANTHI et al. ${ }^{17}$, a especialização esportiva precoce não é uma necessidade para a formação de atletas de alto rendimento, muito menos uma maneira de promoção de cultura esportiva prevalente na idade adulta. No mesmo sentido, alguns autores propóem, tanto para a disseminaçáo do gosto pela prática esportiva, quanto para a formação de atletas de alto rendimento, processos pedagógicos pautados na diversificação de vivências esportivas na infância ${ }^{23,26}$, exposição ao meio competitivo somente após a puberdade ${ }^{10}$ e construção de um ambiente social que permita ao jovem desenvolver-se de modo a respeitar suas fases de maturação e envolver-se com o esporte de modo prazeroso ${ }^{5,8}$.

Mesmo que este processo seja amplamente divulgado pela literatura, alguns autores denunciam que ainda são recorrentes processos pedagógicos que objetivam o alcance da excelência atlética de crianças e jovens em um curto espaço de tempo ${ }^{10,15,22,27-28}$, em clubes, escolas de esporte e em processos de educação formal ${ }^{29}$, e que é possível apontar que sua ocorrência esteja aumentando ao redor do mundo ${ }^{30}$.

$\mathrm{O}$ que as denúncias frente à ocorrência de especialização esportiva precoce apontam é que também existem expectativas, por parte do coletivo social, vinculadas à formação rápida e cada vez mais precoce de novos atletas. Talvez justificadas pelo crescimento do mercado esportivo contemporâneo, a oferta de recompensas financeiras por êxitos em competições ${ }^{17,31}$ e a expectativa pela profissionalização na juventude ${ }^{30}$.

Em muitos casos, treinadores esportivos sofrem pressóes para produzirem resultados competitivos precocemente, tanto por parte das instituiçôes em que trabalham $^{15}$, quanto por pais e familiares das crianças sob sua tutela ${ }^{6}$, por outro lado, cabe a estes sujeitos estarem sempre atentos à intensidade, frequência e expectativa por resultados depositados sobre a criança durante as atividades esportivas. Eles são responsáveis por protegêla no período de iniciação esportiva, proporcionar-lhe experiências positivas e trabalhar para prolongar sua participação no esporte, visto que o principal objetivo deste processo na infância não é formar campeóes ${ }^{32}$.

É possível encontrar na literatura, relatos sobre a ocorrência de processos de especialização precoce em diversas modalidades esportivas ${ }^{15,22,27-28}$. BAKER $^{23}$ aponta que cada modalidade encontra-se atrelada às suas próprias especificidades e características socioculturais. Investigaçóes sobre as diferentes formas de prática esportiva são importantes para 
que se possa melhor compreender tais ocorrências e as implicaçôes para crianças e jovens.

Existe certa dificuldade de realização de estudos longitudinais sobre a formação de futuros atletas, como forma de evidenciar procedimentos pedagógicos positivos e negativos em relação aos processos bem-sucedidos de formação esportiva, visto que o ideal seria acompanhá-los por, pelo menos, nove $\operatorname{anos}^{23}$. Uma alternativa para descrição da trajetória dos atletas é a consulta sobre as percepções dos próprios jogadores quanto às experiências vivenciadas durante sua trajetória esportiva ${ }^{13}$.

Considerando que atletas de alto rendimento tenham conseguido atingir a excelência atlética, e que estes passaram por uma fase de iniciação esportiva, este trabalho busca contribuir com tal discussáo ao apresentar dados sobre o desenvolvimento de jogadores profissionais de voleibol masculino. Toma-se como premissa que estes sujeitos vivenciaram processos de formação esportiva satisfatórios, devido ao alto nível de desempenho alcançado, mas principalmente, por sua continuidade na prática na idade adulta.

Tem-se como questóes centrais desta pesquisa: "atletas profissionais de voleibol (alto rendimento esportivo) vivenciaram um processo de treinamento e especialização precoce?"; "Estes atletas vivenciaram práticas esportivas diversificadas durante sua formação?” A resposta à $1^{\text {a }}$ pergunta pode ajudar a desmistificar crenças sobre o treinamento especializado precoce recorrente na iniciação esportiva. Quanto à $2^{a}$, pode indicar um avanço importante deste trabalho em relaçáo a alguns estudos sobre o voleibol, visto que esta indagação é ainda pouco estudada na modalidade e sua resposta pode sugerir reflexôes sobre a formação de atletas e a oferta de atividades esportivas para as crianças. Assim, foi realizada uma investigação sobre a trajetória esportiva destes atletas, a partir de suas próprias memórias.

O objetivo geral deste trabalho foi investigar o processo de iniciação esportiva de atletas profissionais de voleibol, a partir de suas lembranças pessoais, com foco na análise sobre a possível ocorrência de especialização precoce. Como objetivo específico, buscou-se promover uma reflexão sobre a possível relação entre a ocorrência de treinamento especializado precoce, as vivências diversificadas de práticas esportivas e a formação de atletas de alto rendimento, visto que os sujeitos analisados alcançaram este nível atlético.

\section{Método}

\section{Amostra}

A amostra do estudo foi formada por 52 atletas de sete equipes participantes do Campeonato Paulista ou da Superliga Nacional B de voleibol masculino. A escolha e o recrutamento dos sujeitos ocorreram de acordo com a disponibilidade dos mesmos para a participação na pesquisa.

\section{Procedimentos}

O presente estudo trata-se de uma pesquisa qualiquantitativa. Tal desenho metodológico se caracteriza pelo tratamento estatístico atribuído tanto a variáveis quantitativas discretas ${ }^{a}$, quanto a variáveis qualitativas nominais $^{\mathrm{b}}$ que surgiram no decorrer da pesquisa.

Esta pesquisa foi aprovada pelo Comitê de Ética em Pesquisa da Escola de Enfermagem de Ribeirão Preto.

Para a coleta de dados, aplicou-se um questionário estruturado com 10 questóes abertas, após as sessões de treinos, nos próprios locais de treinamento. Entende-se por questionário uma série de perguntas que devem ser respondidas por escrito pelos sujeitos,

sem a presença do pesquisador ${ }^{33}$. O questionário estruturado caracteriza-se pela impossibilidade de alteração das perguntas, assim como a inserção de novos questionamentos ${ }^{34}$. Neste contexto, as questôes abertas diferenciam-se das fechadas pelo fato de serem respondidas de forma dissertativa, de modo a obter a subjetividade do informante nas respostas. Tal característica demanda, para análise dos dados qualitativos, a utilização de métodos de análise de discurso, com a intenção de extrair os pontos principais e pertinentes da contribuição do sujeito ${ }^{35}$.

O questionário utilizado neste trabalho foi uma adaptação do aplicado por Moriondo et al. ${ }^{36}$, em estudo com atletas profissionais da modalidade atletismo. A adequação necessária ocorreu em relação a algumas especificidades da modalidade voleibol.

Após teste piloto, as perguntas apresentadas aos atletas foram: 1) Quais modalidades você já praticou competitivamente?; 2) Desde que idade você participa do voleibol?; 3) Desde que idade você participa competitivamente do voleibol?; 4) Desde que idade você é remunerado como atleta de voleibol?; 5) Você já recebeu remuneraçáo como atleta de outro esporte?; 6) Qual foi 
a modalidade e com que idade?; 7) Em quais posiçôes já atuou no voleibol?; 8) É especialista em alguma posição?; 9) Caso você tenha alguma posição fixa, desde quando isso acontece?; 10) Recorda-se de algum colega de treino que abandonou o esporte? Por quais motivos?

As respostas foram analisadas e os resultados apresentados através de estatística descritiva, de modo a compor um quadro diagnóstico sobre o perfil de iniciação esportiva vivenciada pelos jogadores.

\section{Análise de resultados}

Por se tratarem de respostas de teor quantitativo discreto, as questóes 2, 3, 4 e 9 não demandaram a aplicação de nenhum método de análise de discurso para que fossem submetidas à estatística descritiva. Por sua vez, as respostas das questôes $1,5,6,7,8$ e 10, por conformarem-se como variáveis qualitativas nominais, foram submetidas a ferramentas metodológicas para análise de discurso, sugeridas pelo método Discurso do Sujeito Coletivo (DSC) ${ }^{37}$.

É importante destacar que este método é proposto por seus autores tanto como uma abordagem qualitativa $^{37-38}$, quanto qualiquantitativa ${ }^{39, c}$, na perspectiva em que privilegia a análise de discursos de modo qualitativo, ao passo em que permite a expressão numérica de incidências de discursos em comum entre os sujeitos de uma determinada amostra. No presente artigo, para padronizar as respostas nominais (questôes $1,5,6,7,8$, e 10) em termos que pudessem ser agrupados de forma homogênea para análise quantitativa, foi realizada uma adaptação deste método, de modo a utilizar algumas de suas ferramentas de análise de discurso (Expressóes-chave e Ideias centrais).

O método DSC pauta-se na análise de respostas oriundas de perguntas abertas, que permitem aos indivíduos se expressarem mais ou menos livremente, produzindo discursos. Embora os criadores do método citem que "...Para a coleta dessa matériaprima, o método mais frequentemente utilizado é a entrevista" ${ }^{17}$ (p.37), os mesmos consideram a utilização de outras fontes de discursos para as análises. A proposta “...consiste, basicamente, em analisar o material verbal coletado extraindo-se de cada um dos depoimentos, artigos, cartas, papers, ideias centrais e/ou ancoragens e as suas correspondentes expressôes-chave" ${ }^{\prime 77}$ (p.16). Em outras palavras, embora seja possível perceber que haja uma preferência pela aplicação das ferramentas de análise do método em discursos oriundos de entrevistas, os autores náo excluem outras fontes de expressão por parte dos sujeitos. Tal posicionamento encontra ressonância na literatura: "O DSC, conforme concebido por seus autores e apresentado em seus livros, consiste em uma modalidade de análise de discursos obtidos em depoimentos verbais ou obtidos em qualquer manifestação discursiva que se possa encontrar em textos e documentos escritos"40 (p.132). É neste sentido que o presente trabalho realizou uma adaptaçáo do método em questáo, de modo a aplicar as ferramentas de análise propostas apenas sobre as respostas das perguntas abertas com características nominais, oriundas dos questionários aplicados.

Tais ferramentas são as expressóes-chave $(\mathrm{ECH})$ e as ideias centrais (IC). As ECH são trechos/pedaços literais do discurso que revelam a essência do depoimento. Trata-se do conteúdo discursivo que corresponde à questáo da pesquisa. Têm a utilidade de apontar qual esfera de análise está sendo abordada pelo sujeito, facilitando uma primeira classificação das respostas. As IC representam o tema do depoimento, os conteúdos a serem destacados e apontados como relevantes para a discussão do tema, pois direcionam para a ocorrência e forma dos eventos analisados. Após as ECH serem selecionadas, as IC foram destacadas e agrupadas, de modo a compor os termos apresentados nos resultados do trabalho ${ }^{37}$.

Deste modo, pôde-se alcançar a padronização terminológica necessária no conteúdo das respostas, o que possibilitou a apresentação dos dados obtidos por meio de estatística descritiva, baseada nos valores de frequências absolutas e relativas de todas as variáveis, e os respectivos valores de média e desvio padrão apenas para a variável idade.

Quanto à apresentação de resultados, quando da utilização das ferramentas de análise do método DSC, os autores citam que "...O Discurso do Sujeito Coletivo pode ser apresentado de várias maneiras, e a presente forma é apenas uma sugestão" ${ }^{\text {37 }}$ (p.56). Destaca-se que a sugestão dos autores refere-se à apresentação de "...um quadro-síntese com as ideias centrais surgidas na análise da questáo”37 (p.56).

Percebe-se em diversos trabalhos que utilizaram este procedimento de análise de discurso, certa diversidade de formas de apresentação de resultados, destacando uma maior preocupaçáo com a associação qualiquantitativa e referindo-se à frequência numeral de indicações de IC pelos sujeitos ${ }^{16,21}$, como também divulgação de dados estritamente qualitativa, não mencionando tal ocorrência numérica, destacando apenas o conteúdo dos DSC em quadros ${ }^{41}$ ou em texto corrido ${ }^{39,42-43}$. Considerando a diversidade de possibilidades e a necessidade de 
análise qualiquantitativa das IC neste trabalho, optou-se por apresentá-las de modo a destacar a frequência de sua incidência.

$\mathrm{Na}$ ausência de dados sobre a idade biológica (estabelecida através de testes maturacionais), a idade cronológica pode ser utilizada como um indicador importante para orientação sobre procedimentos com crianças e jovens ${ }^{11}$. A idade de início do treinamento especializado varia de acordo com as características de cada modalidade ${ }^{32}$. No caso

\section{Resultados e discussão}

A maioria dos sujeitos do estudo aponta que participou de competiçóes em mais de uma modalidade esportiva, além do voleibol (Questão 1: Quais modalidades você já praticou competitivamente?).

De um total de 52 atletas, 38,4\% citaram ter participado somente de competiçóes de voleibol e $61,6 \%$ responderam voleibol e mais outra modalidade esportiva, sendo elas: karatê, natação, futebol, ciclismo, tênis, basquetebol, handebol, tênis de mesa, triatlo e capoeira. Percebe-se que a maioria dos atletas competiu em mais de uma modalidade, embora eles não tenham citado o nível de competição em cada uma delas (FIGURA 1).
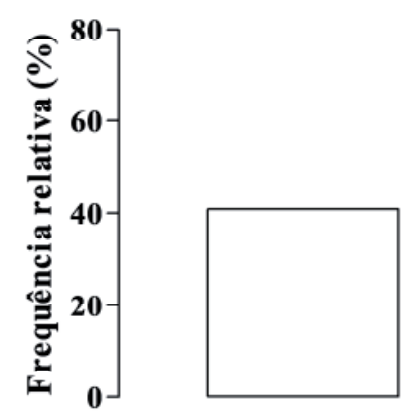

voleibol

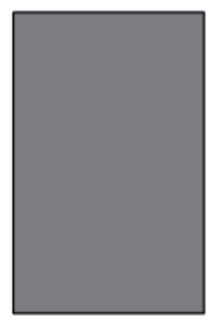

voleibol+outra
FIGURA 1 - Modalidades praticadas de maneira competitiva pelos atletas entrevistados $(\mathrm{n}=52)$.

BAKER $^{23}$ e JAYANTHI et al. ${ }^{17}$ apontam que a vivência em diferentes modalidades é favorável para o desenvolvimento da aptidão esportiva. Como aproximadamente $2 / 3$ dos atletas deste estudo tiveram a oportunidade de vivenciar uma iniciação esportiva com modalidades variadas, esta específico do voleibol, BARBANTI ${ }^{11}$ aponta a iniciação nesta modalidade entre 11 e 12 anos, a especialização no período entre 14 e 15 anos, e o alto rendimento a partir dos 22 anos de idade.

Deste modo, devido à indisponibilidade de dados relativos às idades biológicas dos atletas entrevistados no período de sua iniciação e especialização no voleibol, a idade de 14 anos foi adotada como o limite para consideração sobre a ocorrência ou não de especialização esportiva precoce.

predominância aponta um quadro positivo frente à diversificação de experiências.

É possível encontrar quadros similares na literatura. Por exemplo, atletas dinamarqueses de nível

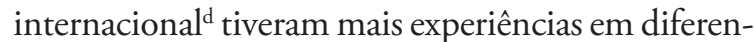
tes modalidades durante a infância do que atletas de nível nacional no mesmo país ${ }^{13}$. E grupo de atletas brasileiros profissionais de atletismo que, em sua maioria, praticaram outras modalidades esportivas durante sua iniciação no esporte ${ }^{44}$.

A crítica sobre a especialização precoce e a vivências em apenas uma modalidade esportiva não se reporta às exigências do alto rendimento para adultos, e sim quando estas são feitas às crianças em fase de iniciação ${ }^{45}$. Um alto grau de especialização é necessário para atingir o esporte de alto nível. Entretanto, para a maioria das modalidades esportivas, o início do treinamento exclusivo em uma única modalidade pode ser atrasado para o final da adolescência, de modo a otimizar o sucesso e minimizar fatores de risco de lesóes e estresse emocional ${ }^{17}$.

Arena e BöHME ${ }^{46}$ sugerem a substituição, durante o período de iniciação esportiva de crianças, do modelo competitivo tradicional por festivais com diversas modalidades, privilegiando a diversidade de experiências esportivas.

Com relação à idade em que os atletas iniciaram o treinamento no voleibol (Questáo 2: Desde que idade você participa do voleibol?), verifica-se que $42,3 \%$ responderam que iniciaram os treinamentos na modalidade entre os 14 e 17 anos e $57,7 \%$ começaram entre os oito e 13 anos de idade. Deste segundo grupo, 17,3\% iniciaram antes dos 11 anos e 40,4\% entre os 11 e 13 anos de idade. A média de início dos treinamentos do grupo total de atletas foi de 12,8 $\pm 2,3$ anos de idade (FIGURA 2). 


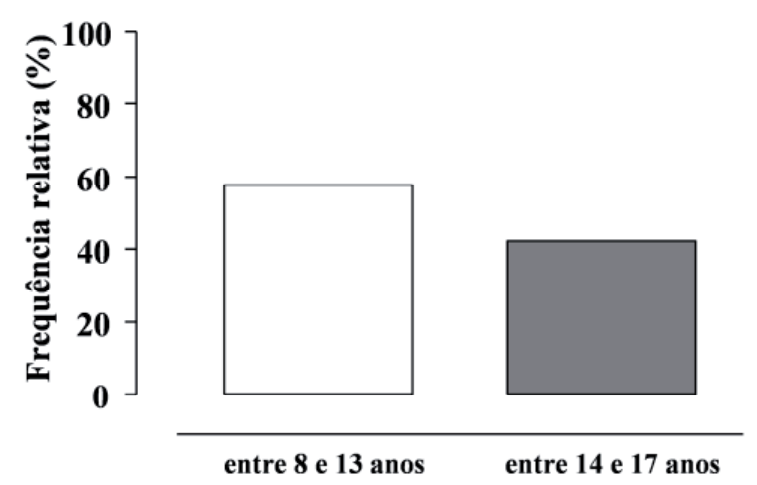

FIGURA 2 -Idade de início da participação em treinamento de voleibol reportada pelos atletas entrevistados $(n=52)$.

Quanto à participação com finalidade competitiva no voleibol (Questão 3: Desde que idade vocêparticipa competitivamente do voleibol?), a maioria dos atletas apontou seu início após os 14 anos de idade.

As respostas revelaram que $32,6 \%$ dos atletas iniciaram a prática competitiva na modalidade entre os nove e 13 anos de idade, enquanto que $67,4 \%$ tiveram a primeira experiência entre os 14 e 18 anos. A média de início em competiçóes foi de 14,3 $\pm 2,1$ anos de idade (FIGURA 3).

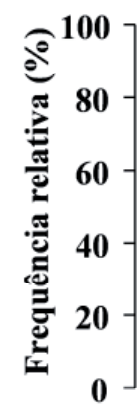

FIGURA 3 - Idade em que os atletas iniciaram a prática competitiva em voleibol $(n=52)$.

Embora a maioria $(57,7 \%)$ dos atletas tenha iniciado sua participação sistematizada na modalidade antes dos 14 anos, deste grupo, aproximadamente 2/3 começou a treinar entre 11 e 13 anos, o que é indicado por BARBANTI ${ }^{11}$ como a idade de início da prática. Quanto ao treinamento que visa a participação em competiçóes, $67,4 \%$ dos atletas teve esta vivência no voleibol após os 14 anos de idade, o que também segundo BARBANTI ${ }^{11}$, representa o momento para tal processo. Quadros similares a este, no qual a maioria de atletas de alto rendimento apresentam um início em atividades predominantemente competitivas em períodos apropriados ou até tardios, podem ser encontrados na literatura em diferentes modalidades esportivas.

Atletas dinamarqueses de nível mundial, de diversas modalidades esportivas, especializaram-se e estrearam em competiçóes nacionais e internacionais em idade mais avançada do que atletas de nível nacional ${ }^{13}$.

No atletismo, Nascimento ${ }^{44}$ apresenta dados relativos à iniciação esportiva de 24 atletas masculinos profissionais, participantes do Troféu Brasil. Deste grupo, 46,2\% iniciaram no treinamento sistematizado do atletismo apenas dos 12 aos 15 anos de idade, outros 46,2\% iniciaram-se dos 16 aos 19 anos e $7 \%$ tiveram seus primeiros contatos com a modalidade acima dos 20 anos de idade.

$\mathrm{Na}$ modalidade futsal, SANTANA et al. ${ }^{47-49}$ investigaram, em três trabalhos distintos, a possível relação entre a especializaçáo precoce e o sucesso esportivo na idade adulta: em estudo com jogadores profissionais da Liga Nacional, tem-se que a maior parte dos atletas (55\%) iniciou a prática competitiva após os 13 anos de idade ${ }^{47}$; Jogadores paranaenses da categoria sub-20 iniciaram no esporte, em média, aos nove anos de idade, tendo ocorrido um vínculo desses jogadores com as federaçóes por cerca de 12 anos. Apesar de terem atuado nas categorias sub-7 e sub-9, aproximadamente $80 \%$ desses atletas não se sagraram campeóes nas mesmas, e se inseriram na prática sistemática e especializada da modalidade durante e após a puberdade ${ }^{48}$; Com jogadores da seleçáo brasileira principal, tem-se que 67\% não participaram de competiçóes e treinamentos sistematizados nas categorias sub-7 e sub- $9^{49}$.

No voleibol feminino, BojıKıan et al..$^{50}$ estudaram jogadoras profissionais e de seleçóes brasileiras de diversas categorias e constataram que estas atletas iniciaramse na prática competitiva, em média, aos 11,6 anos de idade e, especificamente as jogadoras de seleção brasileira adulta, aos 13 anos. Embora não tivessem investigado se as atletas vivenciaram práticas esportivas em outras modalidades além do voleibol e em quais posiçôes atuaram durante sua formação esportiva, os autores apontam para uma relação entre o início tardio $\mathrm{e}$ as maiores chances de sucesso na modalidade.

BojıKIAN $^{51}$ afirma que é comum que atletas com bom desempenho precoce não consigam o mesmo sucesso na idade adulta, e atletas com bom rendimento em fases posteriores tendem a obter melhores resultados do que aqueles especializados precocemente. Os dados desta presente pesquisa com atletas de voleibol masculino fortalecem esta hipótese e ainda mostram que eles iniciaram os treinos e as competiçóes um pouco mais velhos, em média, do que as jogadoras analisadas por BoJıKIAN et al. ${ }^{50}$. 
Existe uma crença entre treinadores e pais de jovens atletas que, quanto mais cedo o talento esportivo for desenvolvido, maiores as chances de sucesso no alto rendimento ${ }^{4,22}$. Tanto os dados apresentados neste estudo, quanto os relatados pela literatura apresentada negam este pressuposto e encontram ressonância em MoEsch et al. ${ }^{13}$, que afirmam que menos tempo de treinamento em idades mais jovens e a especialização somente após a adolescência parecem beneficiar jovens atletas.

Quanto ao início da remuneração dos atletas entrevistados (Questão 4: Desde que idade você é remunerado como atleta de voleibol?), tem-se que a maioria ocorreu após os 14 anos de idade.

Dentre o grupo analisado, 7,6\% responderam ter recebido recompensas financeiras entre os $12 \mathrm{e}$ 13 anos de idade e $92,4 \%$ entre os 14 e 38 anos, com média de idade para a primeira remuneração aos 16,4 \pm 3,7 anos (FIGURA 4).

Embora as recompensas financeiras não se configurem como critério para avaliar a especialização esportiva precoce (de acordo com as definiçóes adotadas $\left.^{12-13}\right)$, é um indicativo de formalização do compromisso competitivo entre o jogador e quem o paga. Os dados mostram que a maioria dos sujeitos analisados não sofreu tal pressão e cobrança por alto rendimento antes dos 14 anos de idade.

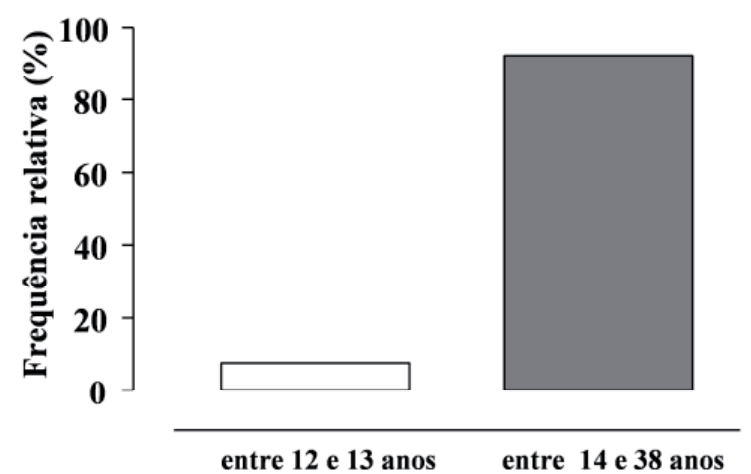

FIGURA 4 - Idade em que os entrevistados receberam sua primeira remuneração como atletas de voleibol $(\mathrm{n}=52)$.

Apenas 1,9\% dos atletas respondeu que havia recebido remuneração pelo futebol aos 13 anos de idade. Os outros 94,3\% dos jogadores nunca receberam recompensas financeiras quando atuavam em modalidade diferente do voleibol e 3,8\% não responderam (Questôes 5 e 6: Você já recebeu remuneraçâo como atleta de outro esporte? Qual foi a modalidade e com que idade?).

Embora a remuneração no futebol tenha acontecido em uma idade anterior ao critério adotado no presente trabalho, ainda assim, é um indicador de não-ocorrência de especialização precoce no voleibol. Quanto ao fato de a maioria dos atletas não ter sido remunerada em outra modalidade, demonstra que, embora grande parte dos entrevistados tenha experiências anteriores em outros esportes (conforme os dados demonstrados anteriormente), não foram alcançados resultados em competiçóes a ponto de obter recompensa financeira, assim como encontrado por Moriondo et al..$^{36}$ em trabalho com atletas profissionais de atletismo.

Quanto à diversidade de experiências em diferentes funções no voleibol (Questão 7: Em quantas posiçôes já atuou no voleibol?), somente $17,3 \%$ dos atletas disseram ter atuado em apenas uma posição, 50\% atuaram em duas posições, 19,2\% em três posiçóes, 3,8\% em quatro posiçóes e 9,7\% em cinco posiçóes (FIGURA 5).

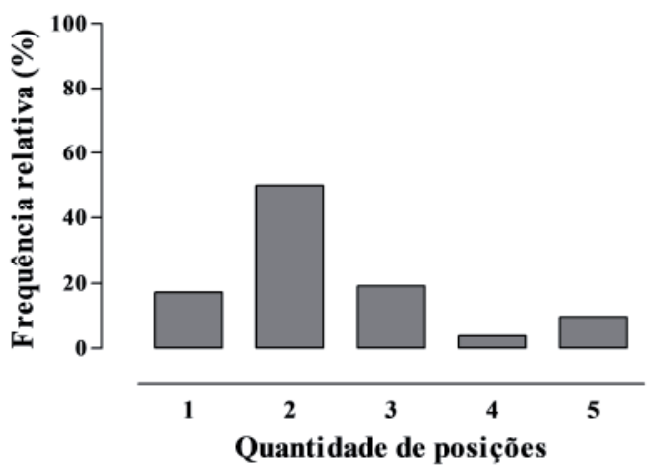

FIGURA 5 - Quantidade de posições em que os atletas já atuaram $(\mathrm{n}=52)$.

Com relação à especialização em um das posições (Questão 8: É especialista em alguma posiçâo?), 15,4\% afirmaram ter se especializado como ponteiros, 9,7\% opostos, $17,3 \%$ levantadores, $17,3 \%$ centrais, $7,7 \%$ líberos e 32,6\% não responderam (FIGURA 6).

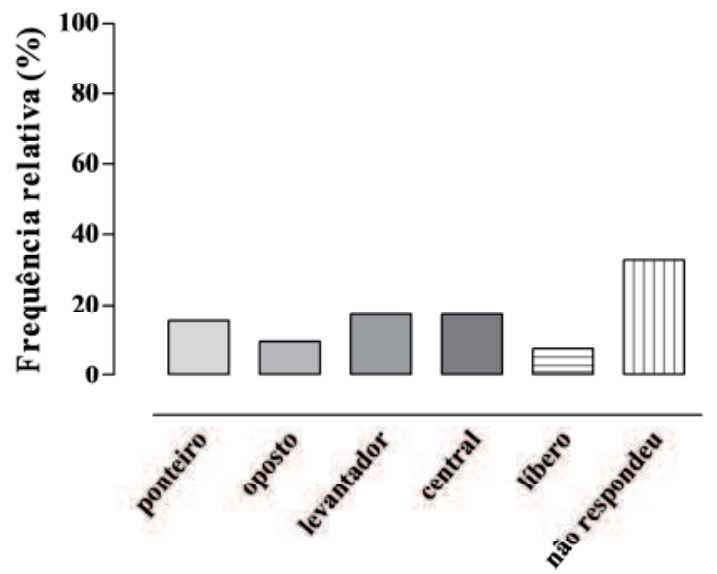

FIGURA 6 - Posição em que os atletas se especializaram $(\mathrm{n}=52)$. 
Quanto à idade de especialização em uma posição (Questão 9: Caso você tenha alguma posição fixa, desde quando isso acontece?), 17,3\% dos sujeitos apontaram entre os nove e 12 anos de idade, 73\% entre os 14 e 32 anos, com média de idade entre todos de 15,5 \pm 3,6 anos, considerando que 9,7\% não responderam a esta questão (FIGURA 7).

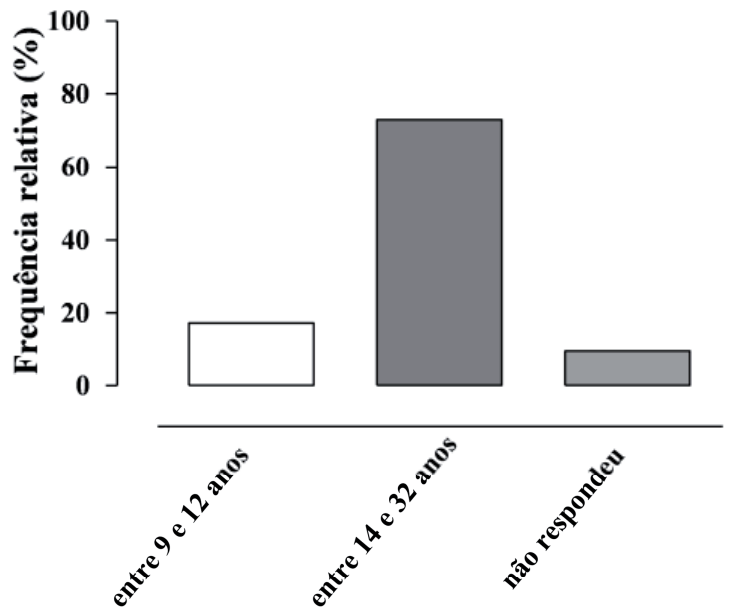

FIGURA 7 - Idade em que os atletas se especializaram na posição em que atuam $(\mathrm{n}=52)$.
Os dados relativos às posiçóes vivenciadas pelos atletas indicam que a minoria $(17,3 \%)$ foi especializada em apenas uma posição antes dos 14 anos de idade e a maioria $(82,7 \%)$ atuou em mais de uma durante sua trajetória esportiva, o que, segundo a literatura, é um procedimento positivo para a formação esportiva ${ }^{52}$.

Por outro lado, atualmente a maioria dos atletas $(67,4 \%)$ se julga especialista em apenas uma posição, algo esperado para o esporte de alto rendimento ${ }^{11}$. Assim, percebe-se que a vivência da maioria dos sujeitos em diferentes funções durante sua formação na modalidade não prejudicou a especialização posterior, o que corrobora Gould ${ }^{23}$ e JAYANTHI et al. ${ }^{17}$.

Quanto às razóes para o abandono da prática esportiva por parte de colegas, (Questão 10: Recordase de algum colega de treino que abandonou o esporte? Por quais motivos?), 7,7\% dos atletas responderam altura insuficiente, $17,3 \%$ trabalho, $23,1 \%$ falta de incentivo, 7,7\% pressão por rendimento, 5,7\% questōes familiares, $17,3 \%$ estudos, $7,7 \%$ lesōes, $5,8 \%$ não se lembram e $7,7 \%$ não responderam (FIGURA 8).

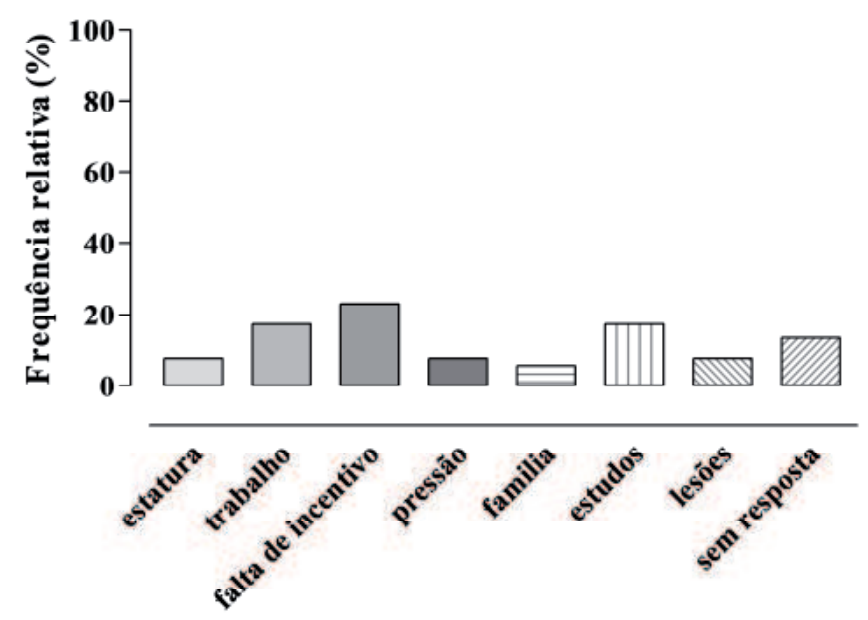

FIGURA 8 - Motivos que provocaram o abandono da modalidade por parte de ex-colegas dos atletas entrevistados.

Mesmo em um quadro no qual os resultados desta pesquisa sugerem que a maioria dos sujeitos não foi especializada precocemente, ainda assim, surgem exemplos de abandono por parte de seus colegas por diversas razóes. É importante destacar que os jogadores não apontaram as idades de abandono de seus ex-colegas de treino. Por isso, tais evidências não podem ser traduzidas como indicadores da presença de especialização precoce nas equipes frequentadas pelos sujeitos desta pesquisa. Estas apenas simbolizam e exemplificam possíveis causas de abandono da prática esportiva e servem de alerta aos treinadores.
Nota-se que os dados coletados coincidem com alguns fatores apontados por ex-nadadores como razōes para o abandono da prática ${ }^{25,53}$.

A especialização esportiva precoce remete, principalmente, à busca imediata por resultados de destaque na infância. Certos fatores e características dos sujeitos são usados por treinadores como alguns dos critérios para seleção de talentos e para a exclusão de jogadores tidos como menos aptos ${ }^{22}$. No voleibol, talvez a "altura" seja o principal destes componentes ${ }^{51}$. Porém, dentre os fatores apresentados pelos sujeitos, este indicador encontra-se 
em menor incidência do que a falta de incentivo, trabalho e estudos.

Com base nos resultados apresentados, conclui-se que a maioria dos jogadores que participou da pesquisa não apresenta indicativos de que tenha sido especializada precocemente no voleibol, visto terem vivenciado modalidades esportivas diferentes e processos de iniciação, especialização e participação em competiçóes no voleibol em idades de acordo com as indicadas pela literatura. Além disso, em média, terem recebido recompensas financeiras somente na segunda metade da adolescência. $O$ fato enfraquece crenças ligadas à especialização prematura como caminho eficaz e positivo para a formaçáo de atletas de alto rendimento.

É necessário assumir que tais dados não garantem que a especialização precoce é, de forma unilateral, causadora de males a todos os jovens que passam por ela (visto que alguns dos atletas investigados vivenciaram situaçóes que poderiam remeter ao treinamento especializado precoce, como experiência exclusiva no voleibol, especialização na modalidade e participação sistemática em competiçôes antes da puberdade). Porém, é possível afirmar, de acordo com o grupo estudado, e confirmaçóes obtidas na literatura, que jovens atletas não precisam ser especializados precocemente para atuarem no esporte de alto rendimento.

Ficou evidenciado que, em relaçáo a este grupo, o início em competiçôes sistemáticas após os 14 anos de idade mostrou-se predominante, visto que a maioria apresentou tal histórico. Talvez o fato de, nos dias de hoje, haver apenas uma categoria de idade abaixo dos
14 anos em algumas federaçóes estaduais no Brasile, seja um fator que possa contribuir para estimular atuais e futuros procedimentos pedagógicos que favoreçam a especialização esportiva a partir da categoria sub-14, o que, de acordo com os dados apresentados neste trabalho, tem-se mostrado positivo.

Tais dados ajudam a desmistificar a crença que quanto mais cedo se inicia o treinamento e a participaçáo em competições, maiores seráo as chances de alcançar o alto rendimento. Fica fortalecido também, o ideal de iniciação e de especialização que priorize o aprendizado por meio de práticas variadas durante a iniciação esportiva, em detrimento da busca por resultados competitivos de destaque antes da puberdade.

As modalidades esportivas distintas manifestamse e se organizam de acordo com as suas próprias características socioculturais ${ }^{54}$. Compreender, contextualizar e propor reflexôes amplas sobre o processo pedagógico no esporte exigem investigaçóes em diferentes tipos de ambientes, além de estudos exploratórios que descrevam as formas de relaçôes sociais pertinentes a cada uma delas.

Acreditamos que as revelaçóes identificadas no presente estudo tenham contribuído para preencher uma lacuna específica neste campo e, em particular, no voleibol masculino. Esperamos que elas venham a estimular novas investigaçóes e aprofundamento de estudos sobre os melhores procedimentos pedagógicos para a iniciação esportiva que priorizem a participação e a manutenção saudável de crianças no esporte em longo prazo.

\section{Notas}

a. “...cujos possíveis valores formam um conjunto finito ou enumerável de números e que resultam, frequentemente, de uma contagem, como por exemplo, número de filhos" ${ }^{55}$ (p.3).

b. "...para a qual não existe nenhuma ordenação nas possíveis realizaçôes" 55 (p.3).

c. Destaca-se que um dos autores deste trabalho ${ }^{39}$ é Fernando Lefevre, um dos criadores do método DSC.

d. Atletas de nível mundial (campeonatos mundiais e/ou Jogos Olímpicos), das seguintes modalidades: canoismo; ciclismo; corrida de orientação; remo; vela; patinação; natação; atletismo; triatlo; levantamento de peso.

e. Para tal afirmação, foram consultadas as home pages de federaçôes estaduais de voleibol, disponíveis em setembro de 2013, com informaçốes sobre as categorias de base do voleibol de quadra (Estados de São Paulo; Rio de Janeiro; Rio Grande do Sul; Santa Catarina; Paraná; Minas Gerais) ${ }^{56-61}$. 


\begin{abstract}
Development of professional volleyball players: relations between elite athletes and early specialization

Although the literature indicates harms of early sport specialization, this procedure remains applicant, based on the belief that sooner training and participation in competition increase the chance of success in highest level. The purpose of this study was to investigate how was the process of sports initiation of 52 male professional volleyball players, in the Paulista Championship and National Superligue. The focus was to analyze the possible occurrence of early specialization and diverse sporting experiences. Data was collected using a questionnaire and analyzed by descriptive statistics. Results show that the majority of the athletes were not early specialized and experienced different practices during training in childhood in different sports. The data support the belief that when sport training focusing on competitive results begins after or during the puberty there are greater chances of success in sports compared to early sport specialization.
\end{abstract}

KEY WORDS: Early sport specialization; Volleyball; Specialization; Sports initiation.

\title{
Referências
}

1. Wiersma L. Riscs and benefits of youth specialization: perspectives and recommendations. Pediatr Exerc Sci. 2000;12:13-22.

2. Coakley J. Sports in society: issues and controversies. 10th ed. Saint Louis: Times Mirror/Mosby College; 2008.

3. Marques RFR. Relaçóes entre o esporte contemporâneo e qualidade de vida. In: Simôes JL, organizador. Educaçáo física, esporte e qualidade de vida. Recife: Universitária UFPE; 2010. p.91-110.

4. Menezes RP, Marques RFR, Nunomura M. Especialização esportiva precoce e o ensino dos jogos coletivos de invasão. Movimento (Porto Alegre). 2014;20:351-73.

5. Freire JB. Pedagogia do futebol. Londrina: Midiograf; 1998.

6. Baker J, Robertson-Wilson J. On the risks of early specialization in sports. Phys Health Educ J. 2003;69:4-8.

7. Bompa TO. Total training for young champions. Champaign: Human Kinetics; 2000.

8. Santana WC. Futsal: metodologia da participação. 2a ed. Londrina: Lido; 2001.

9. Santana WC. Pedagogia do esporte na infância e complexidade. In: Paes RR, Balbino HF. Pedagogia do esporte: contextos e perspectivas. Rio de Janeiro: Guanabara Koogan; 2005. p.1-24.

10. Machado AA, Brandão MRF. Análise contextual da especialização esportiva precoce: novos olhares para novos tempos. In: Machado AA, organizador. Especialização esportiva precoce: perspectivas atuais da psicologia do esporte. Jundiaí: Fontoura; 2008. p.97-108.

11. Barbanti VJ. Formaçáo de jovens esportistas. São Paulo: Manole; 2005.

12. Kunz E. Transformação didático-pedagógica do esporte. Ijuí: Unijuí; 1994.

13. Moesch K, Elbe A-M, Hange M-LT, Wilkman JM. Late specialization: the key to success in centimeters, grams, or seconds (cgs) sports. Scand J Med Sci Sports. 2011;21:282-90.

14. Marques AA. Desporto e futuro: o futuro do desporto. In: Garganta J, editor. Horizontes e órbitas nos treinos dos jogos desportivos. Porto: Universidade do Porto; 2000. p.7-20.

15. Nunomura M, Pires FR, Carrara P. Análise do treinamento na ginástica artística brasileira. Rev Bras Ciênc Esporte. 2009;31:25-40.

16. Massa M, Uezu R, Böhme MTS, Silva LRR, Knijnik JD. Desempenho esportivo no judô olímpico brasileiro: o talento é precoce? Rev Bras Ciênc Mov. 2010;18:5-10.

17. Jayanthi N, Pinkham C, Dugas L, Patrick B, Labella C. Sports specialization in young athletes: evidence-based recommendations. Sports health. 2013;5:251-7.

18. Becker Junior B. Psicologia aplicada à criança no esporte. Novo Hamburgo: Feevale; 2000.

19. Pinto ALS, Lima FR. Atividade física na infância e adolescência. Rev Bras Reumatol. 2001;41:242-46.

20. Dario BES, Barquilha G, Marques RM. Lesóes esportivas: um estudo com atletas do basquetebol bauruense. Rev Bras Ciênc Esporte. 2010;31:205-15.

21. Massa M, Uezu R, Böhme MTS. Judocas olímpicos brasileiros: fatores de apoio psicossocial para o desenvolvimento do talento esportivo. Rev Bras Educ Fís Esporte. 2010;24:471-81. 
22. Cavichiolli FR, Cheluchinhak AB, Capraro AM, Marchi Junior W, Mezzadri F. O processo de formação do atleta de futsal e futebol: análise etnográfica. Rev Bras Educ Fís Esporte. 2011;25:631-47.

23. Baker J. Early Specialization in youth sport: a requirement for adult expertise? High Ability Studies. 2003;14:85-94.

24. Gould D. Positive coaching aliance. Leader's Digest. 2007;9:1.

25. Oliveira G, Araújo Junior I, Andries Junior O, Neto J, Cielo F. A relação entre a especialização precoce e o abandono prematuro da natação. Mov Percep. 2007;8:307-22.

26. Paes RP. Educação física escolar: o esporte como conteúdo pedagógico do ensino fundamental. Canoas: Ulbra; 2001.

27. Arena SS, Böhme MTS. Programas de iniciação e especialização esportiva na grande São Paulo. Rev Paul Educ Fís. 2000;14:184-95.

28. Vieira AF, Bojikian JCM. Especialização no voleibol durante a grande infância. Rev Mackenzie Educ Fis. Esporte. 2008;7:63-70.

29. Knijnik JD, Massa M, Ferretti MC. Direitos humanos e especialização esportiva precoce: consideraçóes metodológicas e filosóficas. In: Machado AA, organizador. Especialização esportiva precoce: perspectivas atuais da psicologia do esporte. Jundiaí: Fontoura; 2008. p.109-28.

30. Mostafavifar AM, Best TM, Myer GD. Early sport specialization, does it lead to long-term problems? Br J Sports Med. 2013;47:1060-1.

31. Marques RFR, Gutierrez GL, Montagner PC. Novas configuraçóes socioeconômicas do esporte contemporâneo. Rev Educ Fís/UEM. 2009;20:637-48.

32. Nunomura M, Carrara PDS, Tsukamoto MHC. Ginástica artística e especialização precoce: cedo demais para especializar, tarde demais para ser campeão! Rev Bras Educ Fís Esporte. 2010;24:305-14.

33. Lakatos EM, Marconi MA. Metodologia do trabalho científico: procedimentos básico, pesquisa bibliográfica, projeto e relatório, publicaçóes e trabalhos científicos. 4a ed. São Paulo: Atlas; 1992.

34. Vergara SC. Métodos de pesquisa em administração. São Paulo: Atlas; 2005.

35. Trivińos ANS. Introdução à pesquisa em ciências sociais: a pesquisa qualitativa em educação. São Paulo: Atlas; 1995.

36. Moriondo LP, Paula EG, Marques RFR. Investigação sobre a ocorrência de especialização precoce no processo de iniciação esportiva de atletas profissionais da equipe Rede de Atletismo de Bragança Paulista. II Congresso de Ciência do Desporto; 2007; Limeira, BR. Limeira: FEF/UNICAMP; 2007.

37. Lefèvre F, Lefèvre AMC. O discurso do sujeito coletivo: um novo enfoque em pesquisa qualitativa (desdobramentos). 2a ed. Caxias do Sul: EDUCS; 2005.

38. Lefèvre F, Lefèvre AMC, Teixeira JJV, organizadores. O discurso do sujeito coletivo: uma nova abordagem metodológica em pesquisa qualitativa. Caxias do Sul: EDUCS; 2000.

39. Schoeps D, Almeida MF, Raspatini PR, Novaes HMD, Silva ZP, Lefevvre F. SIM e SINASC: representação social de enfermeiros e profissionais de setores administrativos que atuam em hospitais no município de São Paulo. Cienc. Saude Colet. 2013;18:1483-92.

40. Sales F, Souza FC, John VM. O emprego da abordagem DSC (discurso do sujeito coletivo) na pesquisa em educação. Linhas. 2007;8:124-45.

41. Rocha ACRP, Landim FLP, Caprara A, Fefévre A, Lefèvre F. O discurso coletivo de ex-hanseniano morador de um antigo leprosário no nordeste do Brasil. Interface: Com Saúde Educ. 2011;15:36:213-23.

42. Mazza MMPR, Lefevre F. Cuidar em família: análise da representação social da relação do cuidador familiar com o idoso. Rev Bras Crescimento Desenvolv Hum. 2005;15:1-10.

43. Castro SS, Lefèvre F, Lefèvre AMC, César CLG. Acessibilidade aos serviços de saúde por pessoas com deficiência. Rev Saúde Pública. 2011;45:99-105.

44. Nascimento ACSL. Pedagogia do esporte e o atletismo: consideraçóes acerca da iniciação e da especialização esportiva precoce [dissertação]. Campinas (SP): Universidade Estadual de Campinas, Faculdade de Educação Física; 2005.

45. Nunomura M, Okade Y, Tsukamoto M. Competition and artistic gymnastics: how to make the most of this experience. Int J Sport Health Sci. 2009;7:42-9.

46. Arena SS, Böhme MTS. Federaçôes esportivas e organização de competições para jovens. Rev Bras Ciênc Mov. 2004; $12: 45-50$.

47. Santana WC, Ribeiro DA. Idades de início de atletas de futsal de alto rendimento na prática sistemática e em competições federadas da modalidade. Pensar Prát. 2010;13:1-17.

48. Santana WC, França VS, Reis HHB. Perfil do processo de iniciação ao futsal de jogadores juvenis Paranaenses. Motriz. 2007;13:181-7. 
Marques RFR, et al.

49. Santana WC, Reis HHB, Ribeiro DA. A iniciação de jogadores de futsal com participação na seleção brasileira. Lect Educ Fís Deportes. 2006;11:96.

50. Bojikian JCM, Silva AVO, Pires LC, Lima DA, Bojikian LP. Talento esportivo no voleibol feminino do Brasil: maturação e iniciação esportiva. Rev Mackenzie Educ Fís Esporte. 2007;6:179-87.

51. Bojikian JCM. Volei vs vôlei. Rev Mackenzie Educ Fís Esporte. 2002;1:117-24.

52. Santana WC. Futsal: apontamentos pedagógicos na iniciação e na especialização. 2a ed. Campinas: Autores Associados; 2008.

53. Darido SC, Farinha FK. Especialização precoce na natação e seus efeitos na idade adulta. Motriz. 1995;1:59-70.

54. Rubio K. Tradição, família e prática esportiva: a cultura japonesa e o beisebol no Brasil. Movimento (Porto Alegre). 2000;6:37-44.

55. Bussab WO, Moretin PA. Estatística básica. 4a ed. São Paulo: Atual; 1987.

56. Federação Paulista de Voleibol. Competiçôes. [citado 29 set. 2013]. Disponível em: http://www.fpv.com.br/bd/ vq_compet.asp.

57. Federação de Voleibol do Rio de Janeiro. Tabela de competiçôes. [citado 29 set. 2013]. Disponível em: http://www. voleirio.com.br/base.asp?pag=tabela.asp.

58. Federação Gaúcha de Voleibol. Campeonatos. [citado 29 set. 2013]. Disponível em: http://www.voleigaucho.com. br/2013/campeonatos.php.

59. Federaçáo Catarinense de Voleibol. Campeonatos. [citado 29 set. 2013]. Disponível em: http://www.voleibol-sc.com. br/novo_site/campeonatos.php.

60. Federação Paranaense de Voleibol. Campeonatos. [citado 29 set. 2013]. Disponível em: http://www.voleiparana.com. br/index.php/inicio.

61. Federação Mineira de Voleibol. Campeonatos. [citado 29 set. 2013]. Disponível em: http://fmvolei.org.br/2012-0916-19-24-23/estaduais.

\begin{tabular}{r|l} 
ENDEREÇo & \\
Renato Francisco Rodrigues Marques & \\
Escola de Educação Física e Esporte de Ribeirão Preto & Recebido para publicação: 30/10/2012 \\
Universidade de São Paulo & 1a. Revisão: 06/11/2012 \\
Av. Bandeirantes, 3900 & 2a. Revisão: 03/10/2013 \\
14040-907 - Ribeirão Preto - SP - BRASIL & 3a. Revisão: 11/02/2014 \\
e-mail: renatomarques@usp.br & Aceito: 12/02/2014 \\
& \\
\hline
\end{tabular}

304 • Rev Bras Educ Fís Esporte, (São Paulo) 2014 Abr-Jun; 28(2):293-304 